\title{
INAPPROPRIATE AFFECT
}

\author{
BY
}

\section{ARTHUR HARRIS AND MARYSE METCALFE}

\author{
From Bethlem Royal Hospital and the Maudsley Hospital and the Institute of Psychiatry, University of London
}

An inability to react emotionally and to "feel" in the highest sense of the word is a disturbance, the concept of which has evolved slowly in psychiatry and has come to assume ever-increasing importance. The grosser degrees of the condition have been known for a long time and recognized as a sign of unfavourable outcome. Thus over 100 years ago, in 1838, Esquirol wrote, "When the sensibility of lunatics is so weakened that they can look at the sun, that they have lost taste and smell, and that they remain unmoved by all discomforts, they will not get well". From Kraepelin's classic account of dementia praecox which first appeared in the earlier edition of his textbook at the end of the nineteenth century, it is clear that he regarded this affective change as one of the cardinal features of this disease entity, for he described not only such signs as causeless, inappropriate laughter, but also subjective complaints of emotional emptiness and lack of feeling (Kraepelin, 1919). At the beginning of this century lack of affect began to attract serious detailed discussion. Stransky described a disturbance of coordination between the intellectual attributes of the whole psyche and the affective attributes, which he called intrapsychic ataxia (Stransky, 1909). Bleuler, in his famous monograph on dementia praecox first published in 1910, built up a vivid clinical picture with illustrative examples from patients he had seen (Bleuler, 1950). He regarded lack of affect as a bad prognostic sign and evidence of chronicity, remarking that "it has been known since the early years of modern psychiatry that an acute curable psychosis became chronic when the affects began to disappear ". For him it is one of the primary signs of schizophrenia and peculiarly typical of that ill-defined group. He recognized that it frequently appears in organic dementias, although it is then overshadowed by changes in the cognitive sphere. Bleuler was the first to observe that these patients have not in fact lost the capacity to react emotionally, but that they react in an unusual and frequently incomprehensible way. We can confirm this from our own experience, having a vivid recollection of several very chronic schizo- phrenic mental hospital inmates whose affect appeared to have been lost, but who showed all tige signs of fear in an exaggerated form when coR fronted with a Benedict-Roth basal metabolisti apparatus (Harris, 1938). This observation has been further borne out by recent experimental work (Malmo, Shagass, and Smith, 1951). The most accurate term for the affect in these patients s? " inappropriate", but we prefer to use as a rufe the more convenient word "flat".

Affective flattening has also been described as. $\vec{a}$ reversible phenomenon produced by oxygen lac (McFarland, 1932; Hoskins, 1937), and by do Economo in encephalitis lethargica (von Econơno, 1931). Some attempts have been made to expla it. Thus Kant (1942) regarded it as a reaction of frustrz tion to mental disintegration and loss of capacio for normal responses. Abély and Abély (1828, after trying to distinguish disturbances in the sep age spheres of mood, emotion, and feelings, decidech hat the phenomena are all explicable on the basis $\vec{\oplus} \overrightarrow{\mathrm{fca}}$ failure of association in the Wundtian sense @os postulated by Bleuler in the case of schizophrenic thought disorder. The orthodox Freudian vies seems to be that it is a symptom of libidinal regression to the ego and of the consequent narcissism (Fenichel, 1934; Symons, 1941).

Bleuler's demonstration that the course of schizophrenic illnesses was variable and the outlook not uniformly bad led to various prognostic enquiries. In these the uniformity with which many different workers found affective flattening to be an adverse factor was striking (Strecker and Willey, 1923; Stalker, 1939; Malamud and Render, 1939; Gildēa and Man, 1943). However, papers also appeargd describing patients with affective flattening who ofid get well (Strecker and Willey, 1927; Rennie, 1949. A follow-up study, covering the whole group of the functional psychoses, found it to be the one clinical sign of definitely grave prognostic significande, although in $11 \%$ of the patients who showed it the disease ran a favourable course (Harris and Nornis, 1954). Many of these authors made it clear that it is not a feature of many illnesses diagnosable @s 
schizophrenia by the criteria usually employed but textbooks continue to describe it as an essential ingredient of that condition. Collins therefore found it necessary to publish descriptions of patients whom most psychiatrists would regard as schizophrenic, but who retained warm affective responses and good emotional contact with the examiner (Collins, 1943).

There is a risk of ambiguity in the discussion of impaired capacity for emotional responses, as various distinct clinical entities can be regarded as occurring in this way. There is the type of character disturbance which manifests itself as a lack of sustained and consistent emotional attitudes in personal relationships, in occupations, and in aims which should influence conduct over long periods. This is seen in many persons classified as psychopaths or hysterics, and is usually recognizable from the patient's own history, although hints of it may emerge in the course of the first interview. In the classical hysterical belle indifference the emotional lack is more apparent than real, and the patient's state becomes comprehensible and appropriate when the role played by his symptoms and the purpose of his illness are understood. The subjective sensation of loss of feeling and inability to react emotionally is frequently spoken of by patients, who are more likely in that case to be suffering from some variety of neurotic or milder depressive condition than frank psychosis, although occasionally schizophrenics and other psychotics will make this complaint. It is a particular feature of syndromes of depersonalization (Schilder, 1928; Ackner, 1954).

The condition that we are concerned with here is a matter of clinical observation and depends on the interpretation of the patients' facial expression, their tone of voice, and the content of their talk. One would think at first sight that these signs are extremely susceptible to differences of opinion. Indeed, Muncie describes at some length the difficulties encountered in the normal recognition of emotions (Muncie, 1948), but Hebb, on the other hand, has strongly defended the use of this recognition in scientific work (Hebb, 1946). Strecker and Willey (1927) describe a spurious affective flattening due to lifelong habits of evasiveness, a personality steeled against any display of feeling and the like, which can be misleading if care is not taken. In practice, however, a surprisingly high measure of agreement is obtainable. Miller, Clancy, and Cumming (1953), in their efforts to assess the mental state of patients by correlating reports from large numbers of different observers, found that the mood of the patient was the item on which there was the nearest approach to unanimity of opinion. There was far more disagreement in their series over such an apparently straightforward matter as the tidiness or untidiness of the patient's dress.

\section{Assessment by Clinical Observation}

A crucial test for the reality of this phenomenon of affective flattening seems to be the presence or otherwise of agreement among independent observers as to its existence in a given patient. We rated 20 schizophrenic patients independently on the scale-no affective flattening, moderate affective flattening, gross affective flattening or incongruity - and found that we agreed in 19.

Then we availed ourselves of the opportunity afforded by an investigation into therapeutic results which involved the assessment of schizophrenic patients each by three separate psychiatrists to ascertain the extent of agreement among these three pscyhiatrists concerning the patient's affective state. The psychiatrists sat together and interviewed the patients one at a time. After the interview each psychiatrist was given a form with spaces for the date, the patient's name and the doctor's name, and the following words:

$$
\begin{aligned}
& \text { Affective state (circle appropriate term) } \ldots \ldots \ldots \ldots \ldots \\
& \qquad \ldots \ldots \text { Elated } \\
& \qquad \ldots \ldots \text { Depressed } \\
& \quad \ldots \ldots \text { Normal } \\
& \ldots \ldots \ldots \text { Moderately flat } \\
& \ldots \ldots \ldots \text { Grossly flat or incongruous }
\end{aligned}
$$

Each completed this form without discussing it with the others.

For the sake of simplicity and clarity and because it is adequate for our purpose, we may take the results on a three-point scale: (1) Grossly flat; (2) moderately flat affect; (3) absence of flattening of affect, including in this group those patients with normal affect and those showing elation or depression. It will be remembered that in the previously mentioned follow-up enquiry neither elation nor depression had an adverse effect in regard to the outcome of the illness (Harris and Norris, 1954).

Out of 23 patients, there was complete agreement between the three assessors in 17, four being rated as grossly flat, seven as moderately flat, and six as showing no affective flattening. In each of the remaining six, two assessors had agreed that the patient's affect was in the moderately flat category, although in four a third assessor had made a rating of absence of affective flattening and in two of grossly flat affect. It is only in the middle ranges, therefore, that there are discrepancies. It seems probable that we are dealing with a continuous scale from absence of affective flattening to the grosser degrees of the disorder, with areas of transition between our inevitably rather artificial three points in which there is scope for disagreement.

There is some evidence that intensity of affect, without regard to the special abnormal quality with which we are dealing in this paper, is of prognostic importance, so that patients who are depressed or agitated or elated have a better chance of recovery (Bayard and Pascal, 1954; Schofield, Hathaway, Hastings, and Bell, 1954); indeed, Harris and Norris's figures could be interpreted in this 
way. It is of interest, therefore, to examine the problems of assessment which an investigation into this point would raise and the extent of agreement achieved by our three psychiatrists in this respect. No patients were thought to be elated, there was complete agreement that three patients were depressed, and that one had normal affect, and in the remaining two patients without affective flattening, two of the assessors rated their affect as normal and one as depressed. In the two last patients, the same assessor rated both as depressed and he had also rated one of the patients, whom the other two had regarded as moderately flat, as depressed, so that he appeared to have a bias in favour of depression. There is scope for disagreement in the interpretation of the signs of depression, which one observer might regard as indicative of a persistent, pathological affect, and another as a natural reaction to the discussion of the patient's unenviable plight during the interview. It is clear that the estimation of intensity, or more precisely whether that intensity has passed the bounds of the normal, is more difficult than that of the peculiar change with which we are concerned at present. This estimation only becomes important if one is regarding the intensity of affect without regard to its appropriateness as the thing to be determined as some workers have done (Bayard and Pascal, 1954; Schofield et al., 1954).

The three psychiatrists were all products of the same training school, although they had received their training at different times. The experiment was repeated with three house physicians, who were in their first six months of psychiatric training, and nine schizophrenic patients. The house physicians were only in agreement on three patients, and in the remaining six, no less than four were regarded as having grossly flat affect by one observer, and no affective flattening by another. It is clear, therefore, that training and experience are necessary before a reliable evaluation can be given. The ratings must be made at the same time as, especially in acute psychoses, changes may be rapid.

\section{Characteristics of Patients Showing Affective Flattening Compared with Other Schizophrenic Patients}

It is of interest to see how a large group of patients showing affective flattening differ from a group of other schizophrenic patients. For every in-patient in the Bethlem Royal and Maudsley Hospitals a document called an item sheet is filled up. On this is recorded a mass of clinical information regarding the history, state on examination, investigations performed, and outcome. The sheets are completed by the house physicians and registrars, i.e., junior doctors undergoing psychiatric training, and checked by the physicians on the senior staff. One of the items recorded is the presence of affective flattening or incongruity. We examined the item sheets of all the patients who had been diagnosed as schizophrenic, admitted to the wards over a period, divided them into two groups on the basis of whether they had or had not shown affective flattening or incongruity, and sought for significant differences between the two groups. Age on admission, sex, psychiatric family history, early life and childhood development, medical history, clinical signs, treatment given, and outcome, were considered. The only significant diffe ences were found in the fields of age, clinical signs, and outcome.

TABLE I

DIFFERENCES BETWEEN PATIENTS WITH AFFECTIVE FLATTENING AND OTHER SCHIZOPHRENICS

\begin{tabular}{|c|c|c|c|}
\hline & $\begin{array}{c}\text { Not } \\
\text { Affectively } \\
\text { Flat }\end{array}$ & $\begin{array}{c}\text { Affectively } \\
\text { Flat }\end{array}$ & 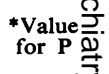 \\
\hline $\begin{array}{l}\text { Total number } \\
\text { Age group 10-19 } \\
\text { Overactive } \\
\text { Impulsive or unpredictable } \\
\text { Posturing, grimacing } \\
\text { mannerisms, stereotype } \\
\text { Schizophrenic type of } \\
\text { thought disorder } \\
\text { Delusions of influence or } \\
\text { passivity } \\
\text { Visual hallucinations } \\
\text { Auditory hallucinations }\end{array}$ & $\begin{array}{r}235 \\
15 \\
29 \\
45 \\
48 \\
99 \\
\\
64 \\
17 \\
83\end{array}$ & $\begin{array}{r}178 \\
29 \\
38 \\
77 \\
87 \\
129 \\
\\
79 \\
38 \\
94\end{array}$ & 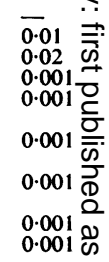 \\
\hline $\begin{array}{l}\text { Outcome: } \\
\text { Recovered or much } \\
\text { improved } \\
\text { Slightly improved or no } \\
\text { change } \\
\text { Worse }\end{array}$ & $\begin{array}{r}113 \\
116 \\
4\end{array}$ & $\begin{array}{r}60 \\
104 \\
13\end{array}$ & 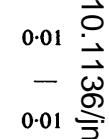 \\
\hline
\end{tabular}

It will be seen that the affectively flat group suffered more from certain other severe psychotic symptoms, tad a less favourable outcome, and had a higher propopion of teenagers.

\section{Test Performance of Schizophrenics Showing Affeêtive} Flattening Compared with Other Schizophrenics

Possible views as to the nature of affective flattegis are (1) that it is a highly specific disturbance not neses sarily accompanied by other defects in mental functioning or (2) that it is part and to some extent a measure of general mental impairment. In the latter case, which seems to us the more probable, those patients who show affective flattening could be expected to give moge evidence of deficit in other fields than those who do no

For this part of the investigation our subjects were 40 patients, 22 women and 18 men, who all displayed gross psychotic symptoms of a classically schizophrerif kind, for example, bizarre delusions, hallucinations wi⿱ a persecutory or fantastic content, passivity feeling, thought disorder, or fatuous, senseless behaviour in various combinations. They were purposely taken git random from patients under treatment at Bethlem Royal and the Maudsley Hospitals and included both in- and out-patients. It was considered undesirable exercise any selection at this stage on such grounds age or length of illness, as this selection might hafe obscured the natural incidence of these variables groups differing with regard to flatness of affect, b\&t patients with markedly dull intelligence were excluded.

Test Battery.-A series of psychological tests was given to each patient and within three days, either before after being tested, each patient was interviewed by the psychiatrist who rated him or her according to the three categories of affect.

Wechsler-Bellevue Test.-A shortened version of the 
Wechsler-Bellevue test, i.e., vocabulary, similarities, and block design subtests, was included because of its satisfactory correlation with the complete test (Hilden, Taylor, and Dubois, 1952).

The Rampton Hospital Sorting Test.-This is the latest version of a series designed to bring out deficiencies in capacity for abstraction (Hall, 1951; Tong, 1955). Cardboard pieces, which show similarities in colour, shape, or decoration, are given to the subject, who has to sort them in five different ways, the scores being inversely related to the number of clues needed to perform each task successfully.

The Nufferno Speed Test.-This in stressed and unstressed versions (Institute of Psychiatry, University of London, 1953) is one with which definite findings in the field of the functional psychoses have recently been achieved (Furneaux, 1953; Shapiro and Nelson, 1955).

The Recognition of Absurdities Test (Hunt, 1935).This test consists of a text containing a certain number of absurdities which the subject is given to read. First he is asked what he thinks of the story. If he does not point out the absurdities he is asked to retell the story in his own words. The third step is to ask him if there is any way in which he could improve on it. The fourth step is to ask him outright whether he can find anything contradictory or absurd. Hunt compared a group of schizophrenics, a group of paretics, and a group of normals. The schizophrenics either never found the absurdities at all or only found them in the last two steps, in contrast to the group of paretics who found them much sooner, and the group of normals who found them all in the first reading.

Wegrocki's Tests.-The battery was completed by a series of tests used by Wegrocki and considered by him to be a measure of generalizing ability (Wegrocki, 1940). There were $(a)$ a set of proverbs which have to be correctly matched with another set of equivalent proverbs and then with a corresponding set of explanations; (b) a list of analogies, the final word of which had been left out and had to be inserted by the subject, for example, " eat is to food as wear is to ..........."; and (c) a list of essential differences where the subject has to underline the word which does not fit the others in a series of four, for example, camera, violin, piano, flute. Wegrocki had found that his schizophrenic patients tended, especially on the proverbs test, to fall into two groups, one which did almost as well as normals and one which did very much worse, paranoids gravitating to the former group and hebephrenics to the latter. This was promising from our point of view since it seemed likely that the hebephrenics would show a higher proportion of flat affects than the paranoids.

The whole battery took about four hours to administer and was given individually to each patient in two sessions of about two hours each. Cooperativeness was estimated on Shakow's scale (Shakow, 1946) and all our patients fell into the three highest grades, most of them being in the two highest grades. In fact, lack of cooperativeness did not seem to influence the results, although some patients were a little lethargic or apt to lose interest.
TABLE II

RESULTS OF BATTERY OF TESTS USED

\begin{tabular}{|c|c|c|c|c|c|}
\hline \multirow[b]{2}{*}{ Test } & \multicolumn{3}{|c|}{$\begin{array}{l}\text { Means of Test } \\
\text { Results }\end{array}$} & \multicolumn{2}{|c|}{$\begin{array}{c}\text { Level of } \\
\text { Significance* }\end{array}$} \\
\hline & 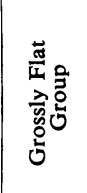 & 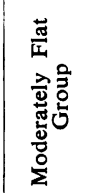 & 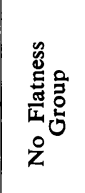 & 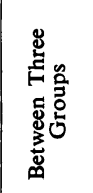 & 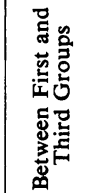 \\
\hline $\begin{array}{l}\text { Wechsler-Bellevue } \\
\text { (I.Q. score) }\end{array}$ & 103 & 115 & 117 & At $2 \%$ & At $2 \%$ \\
\hline Proverbs (error score) & $5 \cdot 75$ & $3 \cdot 75$ & $3 \cdot 46$ & - & - \\
\hline $\begin{array}{l}\text { Essential differences } \\
\text { (error score) }\end{array}$ & $7 \cdot 50$ & $4 \cdot 75$ & $6 \cdot 37$ & - & \\
\hline Analogies (error score) & $10 \cdot 16$ & $8 \cdot 33$ & $7 \cdot 37$ & & - \\
\hline $\begin{array}{l}\text { Sorting } \\
\text { Absurdities (mean no. } \\
\text { of absurdities) }\end{array}$ & $\begin{array}{c}17 \cdot 33 \\
4 \cdot 1\end{array}$ & $\begin{array}{c}20 \cdot 33 \\
4 \cdot 5\end{array}$ & $\begin{array}{c}21 \cdot 56 \\
6 \cdot 1\end{array}$ & At $7 \%$ & - \\
\hline $\begin{array}{l}\text { Nufferno speed } \\
\text { stressed) } \\
\text { solution) }\end{array}$ (time for & $1 \cdot 235$ & $1 \cdot 116$ & $1 \cdot 083$ & $\begin{array}{l}\text { Almost } \\
\text { at } 5 \%\end{array}$ & At $5 \%$ \\
\hline $\begin{array}{l}\text { Nufferno speed (stressed) } \\
\text { (time for solution) }\end{array}$ & $1 \cdot 156$ & 0.920 & 0.994 & $\begin{array}{l}\text { Almost } \\
\text { at } 5 \%\end{array}$ & At $5 \%$ \\
\hline $\begin{array}{l}\text { Wechsler-Bellevue sub- } \\
\text { tests: }\end{array}$ & & & & & \\
\hline $\begin{array}{l}\text { Vocabulary (weighted } \\
\text { score) }\end{array}$ & 11 & $11 \cdot 5$ & $11 \cdot 8$ & - & 一 \\
\hline $\begin{array}{l}\text { Similarities (weighted } \\
\text { score) }\end{array}$ & $9 \cdot 8$ & $11 \cdot 4$ & $10 \cdot 6$ & - & - \\
\hline $\begin{array}{l}\text { Block design (weighted } \\
\text { score) }\end{array}$ & $8 \cdot 3$ & $11 \cdot 5$ & $12 \cdot 3$ & $\begin{array}{l}\text { Beyond } \\
1 \%\end{array}$ & Beyond \\
\hline $\begin{array}{l}\text { Block design (right } \\
\text { solutions) }\end{array}$ & $17 \cdot 7$ & $20 \cdot 2$ & $18 \cdot 5$ & & \\
\hline $\begin{array}{l}\text { Block design (speed } \\
\text { credits) }\end{array}$ & -0.9 & $+5 \cdot 5$ & +6.9 & $\begin{array}{c}\text { Beyond } \\
1 \%\end{array}$ & $\begin{array}{c}\text { Beyond } \\
1 \%\end{array}$ \\
\hline
\end{tabular}

*For test of significance employed see A. R. Jonckheere (1954).

\section{Results}

The results (Table II) are in the expected direction inasmuch as on all tests the mean scores of the grossly flat affect group are inferior to those of the normal group and on all tests but two the grossly flat affect group are inferior to the moderately flat, which in turn are inferior to the normal affect group. The significance of these differences is calculated by a method suitable for studying trends in small groups where the scores do not assume a normal distribution (Jonckheere, 1954). The WechslerBellevue and the Nufferno speed tests differentiate most significantly between the groups. Further analysis of the Wechsler-Bellevue test shows that the difference is due mainly to a poor prrformance on the block design subtest. This difference alone is significant far beyond the $1 \%$ level when the three groups are compared. On the vocabulary and similarities subtests there is scarcely any difference at all between our groups. In the block design subtest the scores were separated into those obtained for correct solutions and those obtained for speed. The results show that it is not the accuracy of the performance but only its speed which is very much lessened in the flat affect group.

Data exist on the Nufferno speed tests for normal 
subjects and for psychotic patients. Our groups with no affective flattening and moderate affective flattening score at the same level as the 50th percentile of these normal subjects, whereas our grossly flat affect group scores just below the 30th percentile of the normals. Our grossly flat affect group performs approximately at the same level as the average for the previously tested psychotics, whereas both the groups without flat affect and with moderately flat affect perform better than these psychotics (Furneaux, 1953).

It is clear, then, that the patients with flat affect show a deterioration in mental speed and this is the most striking finding of this part of the enquiry. The different measures for speed are obviously intercorrelated and the levels of significance obtained between the groups for each of these measures should not be considered as independent from each other.

The Rampton Hospital sorting test differentiates between our groups at a level approaching satisfactory significance. This test is distinguished from the others by demanding a certain degree of inventiveness and by leaving the method of solution to the patient.

Neither Hunt's absurdities test nor Wegrocki's tests differentiate significantly between our groups. Our patients found more absurdities than Hunt's schizophrenics, averaging five as compared with his three. Even more striking is the finding that our patients discovered 28 absurdities, or $37 \%$ of the total, in the first step whereas his group found only one. Similarly with Wegrocki's tests our patients performed better than his schizophrenics, none of our patients falling into his high error category, although they did less well than his normal adult controls and showed a greater range of error scores. Wegrocki's description of the test behaviour of some of his patients and their lower I.Q. range and mean (90 as compared with our patients' 111) suggests that they included a higher proportion of very sick ones who before they fell ill had lower intellectual endowments than ours.
The possibility that factors other than flatness affect had produced the differences between ofr groups in respect of speed must be considered. The groups show little appreciable difference regardieg the age distribution although there are fewer very young patients in the "grossly flat" group. Butt they do differ in length of illness and the presence or absence of physical treatment. (Physical trea ment consisted of insulin coma in all except one

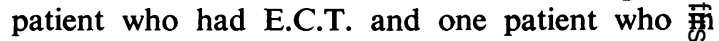
addition to insulin coma had a leucotomy.) The proportion of patients who had received physicgl treatment is higher in the " grossly flat " group th麻 in the " moderately flat" group. The highest pre portion of patients $(62 \%)$ who had no physica्g్l treatment at all were in the "no flatness" group. In terms of length of illness the patients were divide into those of recent onset (less than one year), those who had been ill between one and two years, and those who had been ill for more than two years: The distribution of patients is the same in the first and second groups but in the third group (no flate ness) there was a higher proportion of patients with illness of recent onset.

The subjects are too few for an analysis of varia䢈 so an examination of the influence of these faciogs on one score only, the speed score of the both design test, was undertaken with the result fhent physical treatment and length of illness appeared to have no adverse effect on this score (Table \$I I. Nevertheless, considering the smallness of groups, the possibility that some of the variables which we purposely did not control may hase affected the result must be kept in mind.

\section{Discussion}

The findings that groups of schizophrenic patienfs with flat affect when compared with groups of schizophrenic patients without flat affect show higher incidence of other serious symptoms, a poorer performance on psychological tests involving int lectual processes, and a less satisfactory outcome

TABLE III

COMPARISON OF BLOCK DESIGN SPEED CREDIT SCORES FOR GROUPS WITH VARIED INCIDENCE OF PHYSICAL TREATMENT AND VARYING LENGTHS OF ILLNESS*

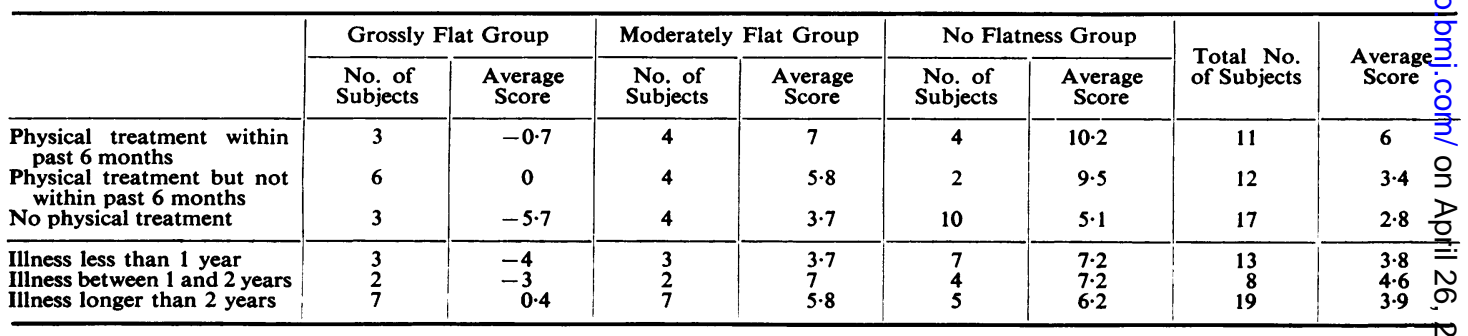

*Physical treatment and length of illness as such have no adverse influence on block design speed credit scores. 
to their illness are consistent with the view that affective flattening is indicative of a severer degree of illness and a greater impairment of mental functioning. The fact that deficit is most clearly demonstrable in the field of speed agrees well with the results of other investigations which show that slowing is the abnormality most easily brought out by present test methods in patients suffering from functional psychoses (Shapiro and Nelson, 1955). Babcock suggested 20 years ago that the apparent lack of emotion in schizophrenia may be due to slowness of response (Babcock, 1933). It is not impossible that speed alone is the responsible factor. The phenomenon of flattening of affect is due to an observer/subject interaction and it may arise from the subject being slower than the observer. This poses the further question as to what produces the slowness. A man may walk slowly because of muscular weakness, cerebellar ataxia, sensory loss, grief, or mental preoccupation. Further work must be directed towards the precise identification of the mental function concerned.

\section{Summary}

The phenomenon of inappropriateness of affect in schizophrenic subjects has been investigated. Trained observers show a high degree of agreement in rating individual patients for its presence or absence. Groups of schizophrenics who exhibit inappropriate affect, when compared with groups of schizophrenics who do not, have a higher incidence of other serious symptoms, a poorer performance in psychological tests, and a less satisfactory outcome to their illness. The deficit in the tests is mainly in the speed at which they solve problems.

We are indebted to Drs. Ackner and Oldham for help in the investigation of the reliability of psychiatrists' ratings and to the Board of Governors of Bethlem Royal Hospital and the Maudsley Hospital who have financed this investigation from their research fund.

\section{REFERENCES}

Abély, X., and Abély, P. (1932). Ann. méd.-psychol., 90 (1), 511. Abely, X., and Abely, P. (1932). Ann. 38.

Babcock, H. (1933). Dementia Praecox : A Psychological Study. Science Press, Lancaster, $\mathrm{Pa}$.

Bayard, J., and Pascal, G. R. (1954). J. consult. Psychol., 18, 122

Bleuler, E. (1950). Dementia Praecox, trans. by Zinkin, J. International Universities Press, New York

Collins, R. T. (1943). J. ment. Sci., 89, 27.

Economo, C. von (1931). Encephalitis Lethargica : Its Sequelae and Treatment Oxford University Press, London.

Esquirol, E. (1838). Des maladies mentales. Baillière, Paris.
Fenichel, O. (1934).

Furneaux, W. D. (1953). Nuffield Research Unit Internal Report F. i, Part 2 .

Gildea, E. F., and Man, E. B. (1943). Amer. J. Psychiat., 99, 496.

Hall, K. R. L. (1951). Brit. J. med. Psychol., 24, 118.

Harris, A. (1938). J. ment. Sci., 84, 735.

Harris, A. (1938). V. (1954). Ibid., 100, 727

Hebb, D. O. (1946). Psychol. Rev., 53, 88.

Hilden, A. H., Taylor, J. W., and Dubois, P. H. (1952). J. clin. Psychol., 8, 321.

Hoskins, R. G. (1937). Arch. Neurol. Psychiat. (Chicago), 38, 1261.

Hunt, J. McV. (1935). Amer. J. Psychol., 47, 458.

Jonckheere, A. R. (1954). Brit. J. statist. Psychol., 7, 93.

Kant, O. (1942). J. abnorm. soc. Psychol., 37, 398.

Kraepelin, E. (1919). Dementia Praccox and Paraphrenia. Livingstone, Edinburgh.

McFarland, R. A. (1932). “The Psychological Effects of Oxygen Deprivation (Anoxemia) on Human Behaviour." Arch. Psychol. (N.Y.), No. 145.

Malamud, W., and Render, N. (1939). Amer. J. Psychiat., 95, 1039. Malmo, R. B., Shagass, C., and Smith, A. A. (1951). J. Personality, $19,359$.

Miller, D. H., Clancy, J., and Cumming, E. (1953). Psychiat. Quart., 27, 439 .

Muncie, W. (1948). Psychobiology and Psychiatry, 2nd ed. Mosby, St. Louis.

Rennie, T. A. C. (1941). Arch. Neurol. Psychiat. (Chicago), 46, 197.

Schilder, P. (1928). "Introduction to a Psychoanalytic Psychiatry." Nerv. ment. Dis. Monograph Series, No. 50. Nervous and Mental Disease Publishing Co., New York.

Schofield, W., Hathaway, S. R., Hastings, D. W., and Bell, D. M. (1954). J. consult. Psychol., 18, 155.

Shakow, D. (1946). The Nature of Deterioration in Schizophrenic Conditions. Coolidge Foundation, New York.

Shapiro, M. B., and Nelson, E. H. (1955). Brit. J. med. Psychol., $28,239$.

Stalker, H. (1939). J. ment. Sci., 85, 1224

Stransky, E. (1909). Uber die Dementia Praecox. Bergmann, Wiesbaden.

Strecker, E. A., and Willey, G. F. (1924). Amer. J. Psychiat., 80, 592.

S1, (1927). J. ment. Sci., 73, 9.

Symons, N. J. (1941). Brit. J. med. Psychol.. 18, 344.

Tong, J. E. (1955). Brit. J. med. Psychol., 28, 19.

Wegrocki, H. J. (1940). "Generalizing A bility in Schizophrenia." Arch. Psychol. $(N . Y$.$) , No. 254$. 